\title{
Factors associated with corneal epithelial defects after pars plana vitrectomy
}

\author{
William Ensor (1D) Tamara Vrabec
}

Received: 28 December 2017/ Accepted: 3 February 2018/Published online: 28 February 2018

(C) The Author(s) 2018. This article is an open access publication

\section{Dear Editor,}

We read with great interest the article by Chiang et al. [1]. The authors identified various factors associated with persistent corneal epithelial defects after pars plana vitrectomy (PPV). This article aids the retinal specialist in identifying at-risk patients.

The authors included patients who underwent PPV under conditions using a prism lens with an interface filled with a sterile viscoelastic lubricant, but did not specify the agent(s) used. Further, it excluded patients who required intraoperative corneal scraping. It would be interesting to know which viscoelastic(s) was used. For example, was the same agent used in all 255 patients included in this study? Did it differ among those who required intraoperative scraping or who developed persistent post-operative epithelial defect?

Most common forms of sterile viscoelastic agents typically include one of several preservatives [2]. These components have been known to cause ocular surface disease, conjunctival toxicity, and corneal epithelial toxicity when administered as solutions for immersion one hour in vitro [3] and topically twice daily in vivo [4]. Is it noted, even at low concentration, some degree of ocular tissue damage attributable to preservatives occurs after one hour of immersion [3].

W. Ensor $(\bowtie) \cdot$ T. Vrabec

Geisinger Medical Center, Danville, PA, USA

e-mail: Wmensor@geisinger.edu
The aforementioned data regarding preservatives were studied under controlled laboratory conditions. While it is unknown whether intraoperative corneal toxicity is dependent on concentration of preservative or exposure time, Chiang et al. [1] identified that longer duration of surgery is associated with higher rates of persistent post-operative corneal epithelial defects.

Garcia-Valenzuela et al. [5] reported that the use of GenTeal gel, a preservative-free preparation, as an intraoperative corneal lubricant was associated with greater corneal clarity compared to the use of Goniosol which contains both EDTA and benzalkonium chloride. Increased frequency of intraoperative corneal scraping in the Goniosol group was attributed to preservatives. This publication did not assess the incidence of persistent post-operative corneal epithelial defects. Various viscoelastic agents developed for intraocular use are also preservative-free.

In summary, we congratulate the authors on their contribution to the literature. While many risk factors were assessed in their investigation, there are more factors to be investigated. Data suggest that the intraoperative use of various corneal lubricants affects corneal clarity; however, it is unknown whether this plays a role in the development of persistent corneal epithelial defects after PPV. This would be an additional area of investigation that would aid retinal specialists in the care of their patients. 


\section{Compliance with ethical standards}

Conflict of interest The authors declare that they have no conflict of interest.

Ethical approval This article does not contain any studies with participants or animals performed by any of the authors.

Informed consent There were no participants in this publication; therefore, informed consent was not obtained.

Open Access This article is distributed under the terms of the Creative Commons Attribution 4.0 International License (http:// creativecommons.org/licenses/by/4.0/), which permits unrestricted use, distribution, and reproduction in any medium, provided you give appropriate credit to the original author(s) and the source, provide a link to the Creative Commons license, and indicate if changes were made.

\section{References}

1. Chiang WY, Lee JJ, Kuo HK et al (2017) Factors associated with corneal epithelial defects after pars plana vitrectomy. Int Ophthalmol. https://doi.org/10.1007/s10792-016-0429-7

2. Bartlett JD, Jaanus SD (eds) (1989) Clinical ocular pharmacology, 2nd edition. Butterworth-Heinemann, Boston, chapter 10 , p 304 Table 10.3

3. Epstein SP, Ahdoot M, Marcus E et al (2009) Comparative toxicity of preservatives on immortalized corneal and conjunctival epithelial cells. J Ocul Pharmacol Ther 25:113-119

4. Labbe A, Pauly A, Liang $\mathrm{H}$ et al (2006) Comparison of toxicological profiles of benzalkonium chloride and polyquaternium-1: an experimental study. J Ocul Pharmocol Ther 22:267-278

5. Garcia-Valenzuela E, Abdelsalam A, Eliott D et al (2003) Reduced need for corneal epithelial debridement during vitreo-retinal surgery using two different viscous surface lubricants. Am J Ophthalmol 2003(136):1062-1066 